\title{
Selective Processing of Food- and Body-Related Information and Autonomic Arousal in Patients with Eating Disorders
}

\author{
Conxa Perpiña* \\ University of Valencia
}

\author{
Janet Treasure and Alyson Bond \\ University of London
}

\author{
Thierry Leonard \\ Hospital Center Saint-Anne of Paris \\ Rosa Baños \\ University of Valencia
}

\begin{abstract}
Both attentional bias (using the modified Stroop Task) and autonomic reactivity (skin conductance level) to food- and body-related information were assessed in 25 patients with eating disorders (15 patients with anorexia, 10 patients with bulimia) and 18 women controls. Patients with anorexia showed the greatest interference in color-naming foodrelated words. However, on this occasion there were no differences in body condition, probably because of heterogeneity of clinical samples and because the control group were staff members, so the target information was very familiar to them. The groups differed in their autonomic reactivity while performing the Stroop, the patients with anorexia responded with higher skin conductance $(p<.036)$. The discussion focuses on the differential profiles shown by samples and on the relationship between cognitive biases and autonomic arousal reactivity.
\end{abstract}

Keywords: eating disorders, attentional bias, autonomic arousal, Stroop task

\begin{abstract}
Se evaluó el sesgo atencional (Tarea de Stroop Modificado) y la reactividad autonómica (Nivel de conductancia de la piel) a la información relacionada con comida y cuerpo en 25 pacientes con trastornos alimentarios ( 15 anoréxicas y 10 bulímicas) y en 18 mujeres normales. Las anoréxicas mostraron la mayor interferencia al nombrar el color de las palabras relacionadas con la comida, aunque las diferencias no resultaron significativas en cuanto a las palabras relacionadas con el cuerpo. Probablemente este resultado puede deberse tanto a la heterogeneidad de las muestras clínicas como a que el grupo control estaba compuesto por personal del hospital, por lo que la información presentada era igualmente familiar para todos ellos. Los grupos se mostraron diferentes en su reactividad autonómica mientras realizaban la tarea Stroop, siendo las anoréxicas las que mostraron una mayor activación $(p<.036)$. Se analizan los perfiles diferenciales exhibidos por las distintas muestras, así como la relación entre sesgos cognitivos y reactividad autonómica. Palabras clave: Trastornos alimentarios, sesgos atencionales, activación autonómica, tarea Stroop
\end{abstract}

This article was partially sponsored by the Conselleria de Cultura, Educació y Ciència de la Generalitat Valenciana (grant convoked in D.O.G.V. number 1783, awarded to Dr. Conxa Perpiñá).

* Correspondence concerning this article should be addressed to Dr. Conxa Perpiñá, Departamento de Personalidad. Facultad de Psicología Avda. Blasco Ibáñez, 21. 46010 - Valencia (Spain). E-mail: perpinya@uv.es 
Research carried out in attentional bias in eating disorders is of interest because it increases our understanding of their underlying psychopathology. The modified Stroop task is one of the tools used to study the nature of this cognitive bias. In a typical Stroop task, subjects are presented with words of varying emotional significance written in different colored inks, and asked to name the color while ignoring the word-meaning. The longer the delay in color-naming (i.e., Stroop interference), the greater the difficulty presumed in avoiding processing the information that forms part of their own domain of concern (MacLeod \& Rutherford, 1992; McNally, Riemann, \& Kim, 1990). Stroop interference is obtained by selecting words relevant to the current concern of individuals and matching them with neutral words. Stroop interference has been found in social phobia (Hope, Rapee, Heimberg, \& Dombeck, 1990), panic disorder (McNally et al., 1990), generalized anxiety disorder (Mathews \& MacLeod, 1985), obsessive compulsive disorder (Foa \& McNally, 1986), post-traumatic stress disorder (McNally, Kaspi, Rienmann, \& Zeitlin, 1990), and spider phobia (Watts, McKenna, Sharrock, \& Trezise, 1986). In the field of eating disorders, several studies (Ben-Tovim \& Walker, 1991; Ben-Tovim, Walker, Fok, \& Yap, 1989; Channon, Hemsley, \& de Silva, 1988; Cooper \& Fairburn, 1992; Cooper \& Fairburn, 1993; Fairburn, Cooper, Cooper, McKenna, \& Anastasiades, 1991; Perpiñá, Hemsley, Treasure, \& de Silva, 1993) have observed selective bias in the processing of food-and body-related words in clinical samples, as well as in dieters and restrained eaters (Cooper \& Fairburn 1992; Perpiñá et al., 1993; Stewart \& Samoluk, 1997). As cognitive theories would predict (Fairburn, Cooper, \& Cooper 1986; Green, McKenna, \& De Silva, 1994), the relationship between affect and cognition posits a bias towards the processing of affectively toned material among subject populations for whom this material is clinically significant. Such attentional biases towards stimuli that are relevant to patients' concerns (in our case, worries about eating, food, body-shape and weight) have been thought to be responsible for the impaired color-naming which is observed in the modified Stroop task and, as a sign of the dysfunctional attitudes, may be one of the factors responsible for maintaining eating disorders (Fairburn et al., 1986).

Another way to assess the emotional response to relevant stimuli is to measure concomitant autonomic arousal. Although desynchrony of the trimodal response systems (behavioral, physiological, and cognitive) is a well-known phenomenon (Mavissakalian, 1987), our hypothesis was that the interference on the Stroop task would be accompanied by an increase in autonomic arousal when the content was emotionally significant.

The main goals of this study were (1) to examine selective processing of food- and body-related information in patients with eating disorders, and (2) to study the autonomic arousal produced during this task.
Method

Subjects

The clinical group was made up of 25 women patients from the Eating Disorders Unit of the Maudsley Hospital in London, specifically, 15 patients with anorexia nervosa and 10 patients with bulimia nervosa, according criteria of the Diagnostic and Statistical Manual of Mental Disorders (American Psychiatric Association, 1987). The control group were 18 healthy volunteer women, recruited by advertisement in the Institute of Psychiatry of the Maudsley Hospital, most of them being Hospital Staff members. The three groups were matched with respect to age.

\section{Measures}

Questionnaires. We administered the following questionnaires to the participants: The Eating Disorder Inventory (EDI: Gamer, Olmsted, \& Polivy, 1983); The Restraint Scale (RS: Herman \& Polivy, 1980); The Hospital Anxiety and Depression Scale (HAD: Zigmond \& Snaith, 1983); and The Spielberger State-Trait Anxiety inventory (STAI: Spielberger, Gorsuch, \& Lushene, 1970).

The Stroop color-naming task. The experimental session consisted of six color-naming tasks. The words were written on cards, in eight columns across the page, each column containing the whole set of 12 words in random order. Each card presented 96 words printed in 4 different colors. Six cards were presented in the following order: control color Stroop; conflicting color Stroop; control food Stroop; food Stroop; control body-size Stroop, and body-size Stroop. See Perpiñá et al. (1993) for more details.

Autonomic arousal. Skin conductance was recorded using a constant voltage method (Contact Precision Instruments Skin Conductance Model) connected to a microcomputer. Silver/silver chloride electrodes were applied to the distal segment of the first two fingers of the participant's left hand. The output of the module was sampled at 100 millisecond intervals during one-minute periods. Samples taken at 2 second intervals were used to obtain the mean skin conductance level (SCL). The number of fluctuations greater than a certain criterion (0.04 microsiemens) was counted.

\section{Procedure}

Each individually tested participant sat in an armchair and rested until she felt comfortable and relaxed. Then, basal SCL was recorded before the Stroop task started. Upon presentation of each card, we obtained two measures: time in seconds required to name the color in which the words were printed (measured by stopwatch), and the SCL recorded by the computer. After the Stroop session, the SCL was again assessed. Finally, the questionnaires were administered. 


\section{Data Analyses}

Food, body, and conflicting-color Stroop conditions were examined separately. Because the color-naming times were not normally distributed, all analyses were performed on reciprocally transformed scores. Multiplied by 100 , this represents the speed of color-naming (the number of words color-named per second). In order to examine whether the different groups showed significant delay in color-naming the target words, or changes in SCL, analyses of variance with repeated measures on the second factor were performed (MANOVA).
To control for differences between cards and groups, two indexes were computed: interference indexes (difference in the speed of color-naming the words on the target cards (food, body (and their respective control word cards), and arousal-increase indexes (difference in SCL on the target and control cards).

\section{Results}

The means and standard deviations of the variables studied in the three groups are displayed in Table 1, in

Table I

Means and Standard Deviation (in brackets) of the Variables studied in the three Groups

\begin{tabular}{|c|c|c|c|c|c|c|c|}
\hline & & \multicolumn{2}{|c|}{$\begin{array}{l}\text { Patients with Anorexia } \\
\qquad N=15\end{array}$} & \multicolumn{2}{|c|}{$\begin{array}{l}\text { Patients with Bulimia } \\
\qquad N=10\end{array}$} & \multicolumn{2}{|c|}{$\begin{array}{l}\text { Controls } \\
N=18\end{array}$} \\
\hline & & $M$ & $(S D)$ & $M$ & $(S D)$ & $M$ & $(S D)$ \\
\hline \multirow[t]{3}{*}{ Age } & Total & 23.8 & $(8.3)$ & 27.8 & $(8.2)$ & 29.3 & $(9.7)$ \\
\hline & Inpatients & 24.3 & $(10.7)$ & & & & \\
\hline & Outpatients & 23.8 & $(2.5)$ & & & & \\
\hline \multirow[t]{3}{*}{ BMI } & Total & 16.2 & $(3.1)$ & 21.1 & $(2.2)$ & 21.1 & $(2.7)$ \\
\hline & Inpatients & 15.4 & $(1.6)$ & & & & \\
\hline & Outpatients & 17.5 & $(4.4)$ & & & & \\
\hline \multirow[t]{3}{*}{ Duration } & Total & 5.9 & $(4.2)$ & 11.0 & (6.5) & 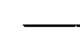 & - \\
\hline & Inpatients & 5.5 & $(3.8)$ & & & & \\
\hline & Outpatients & 6.5 & $(5.0)$ & & & & \\
\hline \multirow[t]{3}{*}{ HD } & Total & 12.7 & $(5.9)$ & 8.5 & (4.6) & 3.3 & $(2.3)$ \\
\hline & Inpatients & 15.2 & $(5.1)$ & & & & \\
\hline & Outpatients & 9.0 & $(5.3)$ & & & & \\
\hline \multirow[t]{3}{*}{ STS } & Total & 60.7 & $(13.9)$ & 44.4 & (14.2) & 31.0 & $(8.1)$ \\
\hline & Inpatients & 65.4 & $(12.9)$ & & & & \\
\hline & Outpatients & 53.5 & $(13.3)$ & & & & \\
\hline \multirow[t]{3}{*}{ STT } & Total & 64.3 & $(10.9)$ & 55.0 & $(14.3)$ & 37.4 & $(7.0)$ \\
\hline & Inpatients & 68.0 & $(8.9)$ & & & & \\
\hline & Outpatients & 58.7 & $(12.2)$ & & & & \\
\hline \multirow[t]{3}{*}{ I } & Total & 14.3 & $(6.5)$ & 13.4 & (5.6) & 1.4 & $(3.3)$ \\
\hline & Inpatients & 14.9 & $(7.0)$ & & & & \\
\hline & Outpatients & 13.3 & $(5.9)$ & & & & \\
\hline \multirow[t]{3}{*}{ III } & Total & 21.5 & $(5.4)$ & 18.3 & (9.5) & 6.7 & $(7.6)$ \\
\hline & Inpatients & 21.1 & $(5.3)$ & & & & \\
\hline & Outpatients & 22.0 & $(6.0)$ & & & & \\
\hline \multirow[t]{3}{*}{ IV } & Total & 14.7 & $(9.2)$ & 10.9 & (8.1) & 0.6 & $(1.5)$ \\
\hline & Inpatients & 17.6 & (8.3) & & & & \\
\hline & Outpatients & 10.5 & $(9.5)$ & & & & \\
\hline \multirow[t]{3}{*}{ VI } & Total & 8.0 & (4.4) & 4.9 & $(4.7)$ & 1.3 & $(2.0)$ \\
\hline & Inpatients & 10.3 & $(3.7)$ & & & & \\
\hline & Outpatients & 4.5 & $(2.7)$ & & & & \\
\hline \multirow[t]{3}{*}{ VII } & Total & 11.2 & $(6.8)$ & 10.0 & (6.1) & 0.4 & $(1.0)$ \\
\hline & Inpatients & 12,9 & $(5.7)$ & & & & \\
\hline & Outpatients & 8.7 & $(8.0)$ & & & & \\
\hline \multirow[t]{3}{*}{$\mathrm{RS}$} & Total & 21.2 & (4.6) & 26.1 & $(6.0)$ & 9.8 & $(6.3)$ \\
\hline & Inpatients & 21.0 & $(4.8)$ & & & & \\
\hline & Outpatients & 21.5 & (4.8) & & & & \\
\hline
\end{tabular}

Age (in years); BMI= Body Mass Index; Duration of the disorder (in years); HD= Hospital Anxiety Depression (Depression); STS= State Anxiety (STAI); STT= Trait Anxiety (STAI); I= Drive for Thinness (EDI); III= Body Dissatisfaction (EDI); IV= Ineffectiveness (EDI); VI= Interpersonal Distrust (EDI); VII= Interoceptive Awareness (EDI); RS= Restraint Scale (RS). 
which only the main demographic and clinical details are shown, as well as those psychometric scales that were relevant in the experimental task, as further analyses revealed.

The three groups were different in several variables. Post-hoc Scheffé's tests $(p<.05)$ revealed that the control group was significantly different from the patient groups in Depression, $F(2,40)=19.10, p<.0001$; trait-anxiety, $F(2,40)=27.91, p<.0001 ;$ Drive for thinness, $F(2,40)$ $=31.34, p<.0001$; Body Dissatisfaction, $F(2,40)=17.86$, $p<.0001$; Ineffectiveness, $F(2,40)=17.64, p<.0001$; Interoceptive Awareness, $F(2,40)=22.59, p<.0001$; and Restraint, $F(2,40)=30.68, \quad p<.0001$. The group of patients with anorexia nervosa was significantly different from controls in Interpersonal Distrust, $F(2,40)=13.52$, $p<.0001$, and from patients with bulimia nervosa and controls in Body Mass Index (BMI), $F(2,40)=15.61, p<$ .001 . All three groups differed in state-anxiety, patients with anorexia being the most anxious group, $F(2,40)=$ $25.36, p<.0001$.

The duration of the disorder was longer for patients with bulimia than for patients with anorexia. Whereas patients with bulimia were all outpatients, $60 \%$ of patients with anorexia were inpatients and $40 \%$ were outpatients. Within the group with anorexia, there were significant differences between in/outpatients in Depression, $t(13)=2.29, p<.04$, and Interpersonal Distrust, $t(13)=3.31, p<.006$, the inpatients obtaining higher scores.

\section{Comparisons on the Stroop Task}

Table 2 displays the results for the Stroop task. In the food condition, analyses of variance revealed a significant main effect of group (patients with anorexia, patients with bulimia, and controls), $F(2,40)=7.28, p<.002$, and main effect of condition (food or control set), $F(1,40)=54.10$, $p<.0001$, but the interaction group $\mathbf{x}$ condition was not significant, $F(2,40)=2.27, p<.117$. As the main effects were significant, a further analysis compared patients (anorexia and bulimia) with controls. There was a significant main effect of group (patients vs. controls), $F(1,41)=14.46, p<.0001$, and main effect of condition (food or control set), $F(1,41)=47.66, p<.0001$, but more important, there was a significant group $\mathrm{x}$ food condition, $F(1,41)=4.55, p<.03$. Post-hoc contrast revealed that interference was greater in patients than in controls, $t(1,41)$ $=2.13, p<.039$.

We decided to compare each clinical group with the controls. Of these comparisons, only one was important: the comparison between anorexic and control groups. Analyses of variance revealed a nearly significant group $\mathrm{x}$ food

Table 2

Means and Standard Deviation (in brackets) for Color-Naming Times in Seconds, Speed, and Interference Indexes

$\begin{array}{ccc}\text { Patients with Anorexia } & \text { Patients with Bulimia } & \text { Controls } \\ N=15 & N=10 & N=18 \\ M \quad(S D) & M \quad(S D) & M \quad(S D)\end{array}$

Control Food

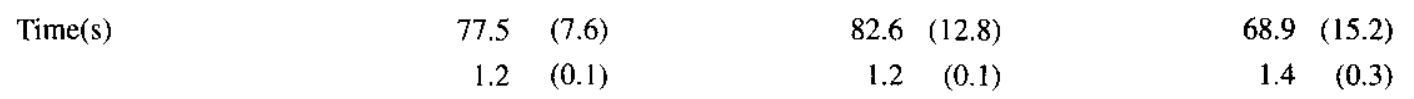

Food

$\begin{array}{lrrrrrr}\text { Time(s) } & 94.3 & (14.0) & 100.7 & (22.2) & 76.5 & (21.7) \\ \text { Speed } & 1.0 & (0.2) & 0.9 & (0.2) & 1.3 & (0.4) \\ \text { Interference } & 0.2 & (0.2) & 0.2 & (0.1) & 0.1 & (0.1)\end{array}$

Control Body

$\begin{array}{lrr}\text { Time(s) } & 85.1 & (9.7) \\ \text { Speed } & 1.1 & (0.1)\end{array}$

$88.2 \quad(9.9)$

$1.1 \quad(0.1)$
$102.6(21.8)$
$0.9 \quad(0.1)$

$0.1 \quad(0.1)$

$\begin{array}{lrr}\text { Time(s) } & 91.4 & (12.4) \\ \text { Speed } & 1.1 & (0.1) \\ \text { Interference } & 0.1 & (0.1)\end{array}$

$0.1 \quad(0.1)$
$74.2(18.0)$

$1.4 \quad(0.3)$

Body

Speed = The reciprocal of the raw scores (seconds) multiplied by 100 ; that is, number of words color-named per second; Interference = speed of color-naming words on the target card minus speed of color-naming words on the control card 
condition, $F(1,31)=3.62, p<.06)$ : the patients with anorexia were slower than controls in naming the color of food-related words. With regard to body sets, there was no significant interaction, either comparing groups altogether, $F(2,40)=1.15, p<.326$, or comparing patients with controls, $F(1,41)=0.53, p<.47$, although the group with anorexia nervosa exhibited less interference compared to patients with bulimia or controls.

In a more detailed analysis of the anorexic sample, we observed that, whereas in- and outpatients showed similar interference on food conditions (inpatients: $M=.21, S D=$ 0.13 ; outpatients, $M=.22, S D=0.21$ ), in the case of body sets, anorexic outpatients revealed less interference $(M=$ $.04, S D=0.12)$ than anorexic inpatients $(M=.10, S D=$ 0.03 ), although this was not statistically significant.

\section{Comparisons on SCL}

Table 3 shows means and standard deviations for mean conductance level in food and body sets. With respect to food conditions, analyses of variance did not reveal a significant main effect of group, $F(2,40)=1.74, p<.189$; or food condition, $F(1,40)=3.34, p<.08$, but the interaction group $\mathrm{x}$ food condition was statistically significant, $F(2,40)$ $=3.62, p<.036$. Post-hoc Scheffé tests $(p<.05)$ showed that patients with anorexia were the group with the highest increase in conductance level, compared to patients with bulimia or controls. Within the group with anorexia, inpatients showed a greater increase $(M=.56, S D=0.77)$ than outpatients $(M=.09, S D=0.14)$, although this difference was not statistically significant.

Regarding body set, analyses of variance did not reveal a significant main effect of group or body conditions, but the interaction group $\mathrm{x}$ body condition was significant, $F(2,40)=3.38, p<.04$. Post-hoc comparisons again showed that patients with anorexia were the group with the highest increase in conductance level, and inpatients showed a higher increase than outpatients $(M=.42, S D=0.71$, and $M=.18$, $S D=0.25$, respectively).

\section{Correlation Analyses}

Correlation analyses between Interference Indexes (Stroop times) and Increase Indexes (SCL) were calculated within each group. Food and Body Increase Indexes correlated significantly only in the group with anorexia, $r$ $=.87, p<.001$. However, there were no significant correlations between Interference Indexes, or between Interference and Increase Indexes. Patients with bulimia were the only group in which an Interference Index (from body set) correlated with an Increase Index in SCL (from food set), $r=.78, p<.007$.

\section{Discussion}

The results indicate that patients were slower than controls in color-naming food words. Patients with anorexia nervosa showed the greatest interference, and in particular, the inpatient anorexic group. However, we could not find significant differences in body condition. Although this result replicates the findings from some studies (Ben-Tovim et al., 1989; Channon et al., 1988), other studies (Cooper \& Fairburn, 1992; Perpin̄á et al., 1993) observed bodyinformation interference in patient groups. Explanations for the failure to replicate body-information interference in some studies could be related to the composition of our samples. With respect to the clinical sample, in this study there is a trend towards differences between in- and outpatients with anorexia nervosa. It would be of interest to investigate this further with larger numbers. Regarding the control group, this was comprised by staff members of the Eating Disorder Unit, so the meaning of the target words was very familiar to them. McNally et al. (1990), in a study using the Stroop to investigate selective processing in panic disorder, assessed both patients with panic disorder and clinicians with experience in this disorder. Although the magnitude of interference was greater in the patients than in the clinicians, this study showed that experts also tended to take longer to color-name threat words than neutral words.

\section{Table 3}

Means and Standard Deviation (in brackets) for SCL (Skin Conductance Level) and Increase Indexes

\begin{tabular}{lcccccc}
\hline & Patients with Anorexia & Patients with Bulimia & \multicolumn{2}{c}{ Controls } \\
& \multicolumn{2}{c}{$N=15$} & $N=10$ & \multicolumn{2}{c}{$N=18$} \\
& $M$ & $(S D)$ & $M$ & $(S D)$ & \multicolumn{1}{c}{$M$} & $(S D)$ \\
\hline Control Food & 6.5 & $(5.3)$ & 3.3 & $(1.9)$ & 5.7 & $(4.3)$ \\
Food & 6.9 & $(5.8)$ & 3.3 & $(1.9)$ & 5.7 & $(4.4)$ \\
Increase & 0.4 & $(0.6)$ & -0.02 & $(0.1)$ & 0.02 & $(0.3)$ \\
Control Body & 6.9 & $(5.9)$ & 3.3 & $(2.1)$ & 5.7 & $(4.3)$ \\
Body & 7.2 & $(6.3)$ & 3.3 & $(1.9)$ & 5.8 & $(4.3)$ \\
Increase & 0.3 & $(0.5)$ & -0.05 & $(0.2)$ & 0.1 & $(0.2)$ \\
\hline
\end{tabular}


The interference on food-information processing was replicated. This result appears to be more robust and may represent a specific core failure for anorexia nervosa. Biases in processing food information may be more "pathological" in the sense that body-related information could play a role in precipitating the disorcler, but food-related information may be more important in its maintenance. Another result from a previous study (Perpiñá et al., 1993) reveals the independence between food- and body-information processing, as evidenced by the fact that food- and body-interference did not correlate in any group. Food- and body-related information may share the same cognitive schemata but they do not seem to share the same semantic cognilive representation. Green and McKenna (1993) found interference on food- and bodyinformation processing using the modified Stroop task in 14year-old female subjects. This finding is consistent with two issues. First, selective processing of such information may also be characteristic of samples preoccupied with these topics, and not only of clinical samples. Second, worries about body shape, physical attractiveness, and dieting are related to the onset of adolescence and confirm the role of cultural preference for thinness in the development of eating disorders (Clarke \& Palmer, 1983). Moreover, Green and McKenna suggested that there may be different developmental onsets for the food- and body-shape Stroop effects, and argued that teenagers (mainly girls) are not actually expressing a genuine worry over their bodies, but are merely indulging in faddish behavior.

Clear differences in autonomic arousal were found between groups in response to both the food- and body-Stroop. Salkind, Fincham, and Silverstone (1980) hypothesized that patients with anorexia would show changes in SCL when asked to imagine food- and body-related stimuli, in the same way that patients with phobia react to relevant stimuli. The changes they found were too small to confirm their hypothesis but they had no control group with which to compare their experimental group. In our study, the group with anorexia nervosa not only showed increased arousal during the foodStroop but also during the body-Stroop, in which they exhibited little interference. It may be that patients with anorexia (mainly outpatients) try to avoid processing bodyrelated information, although autonomic arousal was produced in that condition; however this strategy seems to fail with respect to food-related information because its meaning attracts their attention, and interference, as well as attonomic arousal, is produced. This hypothesis is quite speculative because, in this study, we did not control aspects of information-scanning strategies, although it could coincide with the clinical observation of anorexic patients' avoidance when exposed before a mirror. Further research about this aspect is needed.

On the other hand, patients with bulimia had a lower baseline skin-conductance level than found in a previous study (Leonard, Perpiñá, Bond, \& Treasure, in preparation). This is consistent with the finding of fewer spontaneous fluctuations in electrodermal activity in patients with bulimia
(Calloway, Fonagy, \& Wakeling, 1983). Low skinconductance levels have been found in other psychopathologies characterized by their marked impulsivity and this seems to confirm the premorbid borderline personality traits in patients with bulimia (Vitousek \& Manke, 1994). The absence of an increase in skin conductance during the Stroop task contrasts with the result of one study (Schotte, McNally, \& Turner, 1990) in which patients with bulimia tended to show larger skin-conductance responses than the control sample to the target word (fat) during a dichotic listening task, although this difference did not reach statistical significance.

Finally, although the control sample shows some interference on the Stroop task, this is not accompanied by any differential autonomic arousal. Delayed color-naming may not only be caused by threatening or emotional information but by information familiarity, since representations of foodand body-related information stored in the cognitive lexicon are equally available to both patients and professionals. The difference between them lies in the emotional valence which is negative for patients and which, therefore, results in greater autonomic reactivity.

There are few studies in which both cognitive bias and autonomic reactivity are assessed. Ehlers, Margraf, Davies, and Roth (1988), using a modified Stroop task, and Beck, Stanley, Averill, Baldwin, and Deagle (1992), using a dualtask paradigm, explored attentional bias and psychophysiological responding in patients with panic attack. Whereas patients showed an attentional bias for threatinformation, there were no differences in the autonomic arousal between groups. Furthermore, in the study of Ehlers et al, correlations between interference effects and arousal increases were not significant. In our study, correlational analyses confirmed that Interference Indexes (attentional bias) and Increase Indexes (SC reactivity) are independent, as in the study mentioned above, except for bulimia, in which body interference correlated with food increase. Perhaps, whereas the attentional bias is produced by specific semantic activation in the cognitive representation, reactivity in the autonomic arousal is more unspecified and global.

Attentional bias in eating disorders seems to be a wellestablished phenomenon. How, and in which way, it is related to autonomic activity needs further research. In addition, the different subtypes of anorexia and bulimia nervosa, which have finally been acknowledged by the Diagnostic and Statistical Mantal of Mental Disrorders (American Psychiatric Association, 1994) would have to be distinguished.

We conclude that abnormal processing of food-related information is a consistent finding in anorexia nervosa but there is less reliability in the finding of abnormal processing of body-shape-related information in both anorexia and bulimia nervosa. Patients with anorexia nervosa show increased emotional arousal in response to these concerns. 
Surprisingly, patients with bulimia nervosa show a low baseline. The limitation of this study is mainly related to the small size of the samples, and because of this, we could not explore differences within the patient groups. For example, patients with anorexia nervosa who are inpatients are actively being fed to gain weight, whereas outpatients may not be undergoing any change. Likewise, there may be differences between restricting and purging subtypes. The specificity of the cognitive and emotional reaction to the main concerns of eating disorders (food-and body-related information) requires further investigation.

\section{References}

American Psychiatric Association. (1987). Diagnostic and Statistical Manual of Mental Disorders (3rd edition, revised). Washington, DC: APA Press.

American Psychiatric Association. (1994). Diagnostic and Statistical Manual of Mental Disorders (4th edition). Washington, DC: APA Press.

Beck, J. G., Stanley, M. A., Averill, P. M., Baldwin, L. E., \& Deagle III, E. A. (1992). Attention and memory for threat in panic disorder. Behavior Research and Therapy, 30, 619-629.

Ben-Tovim, D. I., \& Walker, M. K. (1991). Further evidence for the Stroop test as a quantitative measure of psychopathology in eating disorders. International Joumal of Eating Disorders, 10, 609-613.

Ben-Tovim, D. I., Walker, M. K., Fok, D., \& Yap, E. (1989). An adaptation of the Stroop test for measuring shape and food concerns in eating disorders: A quantitative measure of psychopathology? International Journal of Eating Disorders, 8, 681-687.

Calloway, P., Fonagy, P., \& Wakeling, A. (1983). Autonomic arousal in eating disorder: further evidence for the clinical subdivision of anorexia nervosa. British Journal of Psychiatry, 142, 38-42.

Channon, S., Hemsley, D., \& de Silva, P. (1988). Selective processing of food words in anorexia nervosa. British Joumal of Clinical Psychology, 27, 259-260.

Clarke, M. G., \& Palmer, R. L. (1983). Eating attitudes and neurotic symptoms in university students. British Journal of Psychiatry, 142, 299-304.

Cooper, M. J., \& Fairburn, C. G. (1992). Selective processing of eating, weight, and shape in anorexia nervosa and bulimia nervosa, Behaviour Research and Therapy, 30, 501-511.

Cooper, M. J., \& Fairburn, C. G. (1993). Demographic and clinical correlates of selective information processing in patients with bulimia nervosa. International Journal of Eating Disorders, 13, 109-116.

Ehlers, A., Margraf, J., Davies, S., \& Roth, W. (1988). Selective processing of threat cues in subjects with panic attacks. Cognition and Emotion, 2, 201-219.

Fairburn, C. G., Cooper, P. J., Cooper, M. J., McKenna, F. P., \& Anastasiades, P. (1991). Selective information processing in bulimia nervosa. International Journal of Eating Disorders, 10, 415-422.
Fairburn, C. G., Cooper, Z., \& Cooper, P. J. (1986). The clinical features and maintenance of bulimia nervosa. In K.D. Brownell \& J.P. Foreyt (Eds.), Physiology, psychology, and treatment of the eating disorders (pp. 389-404). New York: Basic Books.

Foa, E. B., \& McNally, R. (1986). Sensitivity to feared stimuli in obsessive-compulsives: a dichotic listening analysis. Cognitive Therapy and Research, 10, 477-485.

Garner, D. M., Olmstead, M. P., \& Polivy, J. (1983). Development and validation of a multidimensional eating disorder inventory for anorexia nervosa and bulimia. International Journal of Eating Disorders, 2, 15-34.

Green, M. W., \& McKenna, F. P. (1993). Developmental onset of eating related color-naming interference. International Joumal of Eating Disorders, 13, 391-397.

Green, M. W., McKenna, F. P., \& De Silva, M. S. L. (1994). Habituation patterns to colour naming of eating-related stimuli in anorexics and non-clinical controls. British Joumal of Clinical Psychology, 33, 499-508.

Herman, C. P., \& Polivy, J. (1980). Restrained eating. In A. J, Stunkard (Ed.), Obesity (pp. 208-225). Philadelphia: Saunders.

Hope, D. A., Rapee, R. M., Heimberg, R. G., \& Dombeck, M. J. (1990). Representations of the self in social phobia: vulnerability to social threat. Cognitive Therapy and Research, 14, 177-189.

Leonard, T., Perpiñá, C., Bond, A., \& Treasure, J. (in preparation). Assessment of test-meal induced autonomic arousal in anorexic, bulimic, and control females.

MacLeod, C., \& Rutherford, E. M. (1992). Anxiety and the selective processing of emotional information: mediating roles of awareness, trait and state variables, and personal relevance of stimulus material. Behaviour Research and Therapy, 30, 479-491.

Mathews, A., \& McLeod, C. (1985). Selective processing of threat cues in anxiety states. Behaviour Research and Therapy, 23, $563-568$.

Mavissakalian, M. (1987). Trimodal assessment in agoraphobia research: Further observations on heart rate and synchrony/desynchrony. Journal of Psychopathology and Behavioral Assessment, 9, 89-98.

McNally, R. J., Kaspi, S. P., Riemann, B. C., \& Zeitlin, S. B. (1990). Selective processing of threat cues in post-traumatic stress disorder. Joumal of Abnormal Psychology, 95, 398-402.

McNally, R. J., Riemann, B. C., \& Kim, E. (1990). Selective processing of threat cues in panic disorder. Behaviour Research and Therapy, 28, 407-412.

Perpiñá, C., Hemsley, D., Treasure, J., \& de Silva, P. (1993). Is the selective information processing of food and body words specific to patients with eating disorders? Intemational Joumal of Eating Disorders, 14, 359-366.

Salkind, M. R., Fincham, J., \& Silverstone, T. (1980). Is anorexia nervosa a phobic disorder?: A psychophysiological enquiry. Biological Psychiatry, 15, 803-808.

Schotte, D. E., McNally, R. J., \& Turner, M. L. (1990). A dichotic listening analysis of body weight concern in bulimia nervosa. International Journal of Eating Disorders, 9, 109-113. 
Spielberger, C. D., Gorsuch, R. L., \& Lushene, R. E. (1970). StateTrait Anxiety Inventory. Palo Alto, Ca.: Consulting Psychologist Press.

Stewart, S. H., \& Samoluk, S. B. (1997). Effects of short-term food deprivation and chronic dietary restraint on the selective processing of appetitive-related cues. International Joumal of Eating Disorders, 21, 129-135.

Vitousek, K., \& Manke, F. (1994). Personality variables and disorders in anorexia nervosa and bulimia nervosa. Journal of Abnormal Psychology, 103, 137-147.
Watts, F. N., McKenna, F. P., Sharrock, R., \& Trezise, L. (1986). Color Naming of phobia-related words. British Journal of Clinical Psychology, 25, 253-259.

Zigmond, A. S., \& Snaith, R. P. (1983). The Hospital Anxiety and Depression Scale. Acta Psychiatrica Scandinavica, 67, 361-370

Received December 17, 1996 Revision received September 15, 1997 Accepted November 19, 1997 